\title{
A PRÁTICA NO ESTÁGIO SUPERVISIONADO PARA EDUCAÇÃO PÓS-CONTEMPORÂNEA: A CONTRIBUIÇÃO TEÓRICA DO EMPREENDEDORISMO, INCLUSÃO, INTERDISCIPLINARIDADE E SUSTENTABILIDADE NA FORMAÇÃO DO PROFESSOR
}

\author{
PRACTICE IN SUPERVISED INTERNSHIP FOR POST- \\ CONTEMPORARY EDUCATION: THE THEORETICAL \\ CONTRIBUTION OF ENTREPRENEURSHIP, INCLUSION, \\ INTERDISCIPLINARITY AND SUSTAINABILITY IN TEACHER \\ EDUCATION
}

Geiza Gláucia Zeferino Viegas ${ }^{1}$ Lídia Costa ${ }^{2}$

Vagner Luciano de Andrade ${ }^{3}$

\section{RESUMO}

A prática escolar pós-contemporânea, fundamenta-se em questões e temáticas, cada vez, mais diferenciadas como: Empreendedorismo, Inclusão, Interdisciplinaridade e Sustentabilidade, que por sua vez precisam ser revistas desde a formação na licenciatura até sua percepção e aplicação no contexto escolar. Vê-se que os pensamentos teóricos aprendidos no decorrer dos cursos de Licenciatura promovem uma visão reflexiva incompleta em relação à escola. Este texto tem como finalidade debater sobre a contribuição do estágio curricular obrigatório supervisionado como ferramenta necessária à construção e formação do licenciado. Embasado na Educação do Século XXI, metodologicamente utilizou-se de uma revisão bibliográfica vertendo para quatro pilares Empreendedorismo, Inclusão, Interdisciplinaridade e Sustentabilidade. Neste sentido, o estágio curricular obrigatório é essencial para a didática do futuro professor ao possibilitar o entendimento sobre questões relacionadas ao ambiente escolar atual como a rotina, as atividades extracurriculares, o planejamento, dentre outros aspectos. Desse modo, é relevante a discussão sobre o estágio curricular obrigatório nos cursos de Licenciatura, visto que no universo acadêmico têm-se estudos e compartilhamentos de ideias integradas à vivência temática da prática, sendo necessário um aprofundamento e reflexão sobre à futura atuação pedagógica empreendedora, inclusiva, interdisciplinar e sustentável.

Palavras-chave: Estágio; Empreendedorismo; Inclusão; Interdisciplinaridade; Sustentabilidade.

\footnotetext{
${ }^{1}$ Licenciada em Letras (PUC-Minas). Graduada em Pedagogia (UNICESUMAR - EAD). Pósgraduada em Neuropsicopedagogia (FAMARC). Especialista em Atendimento Educacional Especializado (UNICESUMAR - EAD). Docente na rede pública municipal de Contagem e na rede particular de Belo Horizonte. Orcid: 0000-0002-2479-8497. Link do Lattes: http://lattes.cnpq.br/0366179662698917. E-mail: geizazefs@ yahoo.com.br.

${ }^{2}$ Licenciada em Educação do Campo, com habilitação em Ciências Sociais e Humanidades (FaE/UFMG) e licenciada em Letras/LIBRAS (FIAR). Pós-graduada em Educação Especial e Inclusiva (FANAN). E-mail: lidia_mynas@ hotmail.com.

3 Bacharel-licenciado em Geografia e Análise Ambiental (UNI-BH/2007), Licenciado em História (UNICESUMAR/2018) e especialista na área de Educação, Patrimônio e Paisagem Cultural (Filosofia da Arte e Educação, Metodologia de Ensino de História, Museografia e Patrimônio Cultural, Políticas Públicas Municipais). Licenciado em Ciências Biológicas (FIAR/2018), Tecnólogo em Gestão Ambiental (UNICESUMAR/2019) e especialista na área de Educação, Patrimônio e Paisagem Natural (Administração escolar, Orientação e Supervisão, Ecologia e Monitoramento Ambiental, Gestão e Educação Ambiental, Metodologia de Ensino de Ciências Biológicas). Orcid: 0000-0003-4679-7177. CV Lattes: http://lattes.cnpq.br/3803389467894439. E-mail: botafogo321@yahoo.com.br.
}

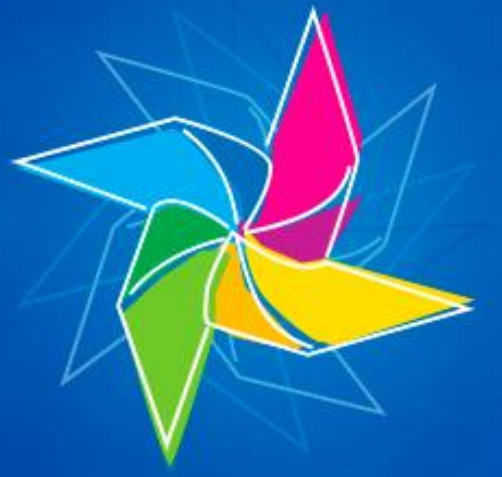




\begin{abstract}
Post-contemporary school practice is based on increasingly differentiated issues and themes such as: Entrepreneurship, Inclusion, Interdisciplinarity and Sustainability, which in turn need to be revised from undergraduate education to their perception and application in the school context . It is seen that the theoretical thoughts learned during the Licentiate courses promote an incomplete reflective view in relation to the school. This text aims to discuss the contribution of the supervised compulsory curricular internship as a necessary tool for the construction and training of the graduate. Based on 21st Century Education, methodologically, a bibliographic review was used, focusing on four pillars: Entrepreneurship, Inclusion, Interdisciplinarity and Sustainability. In this sense, the mandatory curricular internship is essential for the didactics of the future teacher, as it enables the understanding of issues related to the current school environment, such as routine, extracurricular activities, planning, among other aspects. Thus, it is relevant to discuss the mandatory curricular internship in undergraduate courses, given that in the academic universe there are studies and sharing of ideas integrated into the thematic experience of the practice, requiring further study and reflection on the future entrepreneurial pedagogical performance, inclusive, interdisciplinary and sustainable.
\end{abstract}

Keywords: Internship; Entrepreneurship; Inclusion; Interdisciplinarity; Sustainability.

\title{
INTRODUÇÃO
}

As palavras mestre, professor e preceptor, sempre marcaram, direta e indiretamente, a vida e a realidade das pessoas. Em diferentes tempos e espaços, os seguintes sinônimos: docente, educador, guia, instrutor, lecionador, mentor, mestre, orientador, pedagogo, preceptor, professor, foram entendidos de formas distintas no projeto societário que os concebeu. Para um amplo entendimento da ação docente, entende-se por licenciado como todo/a aquele/a formado/a em licenciatura e, portanto, plenamente apta/o a atuar na educação. O presente artigo utilizará, de maneira alternada, os termos educador e professor, por serem mais comuns. Atualmente, a formação de docentes se dá por três modalidades distintas, a Formação Pedagógica, a Licenciatura Plena e a Segunda Licenciatura, sendo ofertados cerca de dezoitos cursos regulares ${ }^{1}$ : Artes Visuais, Ciências Biológicas, Educação Especial, Educação Física, Educação Religiosa ${ }^{2}$, Filosofia, Física, Geografia, História, Informática, Letras - Espanhol, Letras - Inglês, Letras - LIBRAS, Letras - Português, Matemática, Pedagogia, Química e Sociologia. Na formação dos Licenciados, o estágio curricular obrigatório supervisionado é momento de vivenciar a prática escolar e articular o que foi discutido e estudado no decorrer de todo o curso.

Sabe-se que no cotidiano escolar existem desafios, como estudantes indisciplinados,

\footnotetext{
1 A escola regular é aquela que segue a educação comum, com os níveis de ensino e faixas etárias estabelecidas. A educação especial é voltada ao ensino e aprendizagem de alunos com deficiências e transtornos do desenvolvimento e aprendizado. Esses estudantes podem estudar em escolas do ensino regular ou em escolas especiais. De modo geral, mesmo com os avanços dos últimos anos, o ensino regular não consegue atender de maneira satisfatória alunos com deficiência, o que tem estimulado o debate sobre a escola inclusiva, pensada para o convívio e aprendizado de todos os alunos. Transcrito na íntegra de https://www.educamaisbrasil.com.br/educacao/noticias/ensino-regular-o-que-e-e-como-funciona. Acessado em 10/11/2020.

2 No país, ainda é pequena a quantidade de licenciaturas em Ciências da Religião, sendo a titulação outorgada ao docente, por meio de cursos de especialização.
} 
dificuldades de aprendizagem, inclusão de deficientes, entre outros elementos para os quais é necessário buscar meios de superação e promoção da igualdade e democracia. Neste sentido, buscar uma teoria que contemple questões escolares ajudará em algumas situações específicas inserindo temáticas emergenciais como Empreendedorismo, Inclusão, Interdisciplinaridade e Sustentabilidade. Assim, qual seria a contribuição teórica do Empreendedorismo, Inclusão, Interdisciplinaridade e Sustentabilidade na formação do professor e onde o estágio entraria nesse aspecto? A questão do Empreendedorismo, da Inclusão, da Interdisciplinaridade e da Sustentabilidade, por sua vez, adquire status de discussão recentes no âmbito das práticas escolares, bem como, o conhecimento e a discussão desses quatro pilares é uma conquista recente no campo da educação brasileira.

É preciso formar cidadãos empreendedores, inclusivos, interdisciplinares e sustentáveis, que emancipados, sejam protagonistas na sociedade. Mas os cursos de licenciatura ainda se encontram em adaptação frente à estas demandas pós-modernas, sendo que estas quatro temáticas ainda se se consolidaram como disciplinas obrigatórias. Por isso, ao realizar o estágio curricular obrigatório, o futuro docente atentar-se-á às essas questões metodológicas, visto que sem a prática, a teoria não existe e nem o contrário.

Este estudo tem como objetivos, discutir a importância de se aplicar na formação docente discussões e formações temáticas vinculadas a uma nova escola, empreendedora, inclusiva, interdisciplinar e sustentável, e justifica-se pela emergência da temática, tão atual e necessária, e que, por sua vez, ainda não se constitui como disciplina obrigatória nos cursos de licenciatura e que por isso, é aplicável à vivência e observação realizadas no âmbito do estágio. A metodologia basicamente se estruturou em uma revisão bibliográfica acerca do tema. Compreende-se, assim, que o ponto de partida de estudos teóricos que Empreendedorismo, Inclusão, Interdisciplinaridade e Sustentabilidade são tópicos proveniente de demandas surgidas no espaço escolar, bem como fora dele. Portanto, são demandas inegáveis advindas da transição entre os séculos XX e XXI. Logo, não se forma um licenciado, sem essa discussão temática no âmbito acadêmico, assim como sem vivenciar o exercício do fazer pedagógico e suas tessituras.

Especialmente, a possibilidade de uma educação pós-contemporânea gerada nas últimas décadas impulsionou grandes alterações em toda educação mundial, e fundamentou a elaboração da Política Nacional de Educação Brasileira na perspectiva da educação póscontemporânea. Questões de Empreendedorismo, Inclusão, Interdisciplinaridade e Sustentabilidade tem orientando tecnicamente as transformações do sistema de ensino, transformando-os em sistemas educacionais inovadores, registrando uma evolução sem precedentes no acesso à escola comum e à prática social decorrente dela (BRASIL, 2008). 
Essa revolução decorre pioneiramente da inserção da pessoa deficiente em ambientes escolares inclusivos, remodelando todo o modelo societário pretérito marcado historicamente por exclusão, preconceito, rejeição, negação. De acordo com Oliveira, Abreu e Oliveira (2013, p. 186):

\begin{abstract}
Surge então, no cenário pós-moderno de educação, um novo tipo de mentalidade cultural, que representa a reflexão crítica da razão humana (ADORNO; HORKHEIMER, $1985^{3}$ ). A pós-modernidade se configura como uma nova postura em educação, renegando a prática educativa moderna dos professores que não respondem aos problemas atuais da educação contemporânea. A reflexão que surge em educação é baseada na decisão de confronto com a escola tradicional. Nessa reflexão estão envolvidos não somente a razão, mas outras faculdades que caracterizam a visão ampla do problema educacional. As faculdades sensíveis também adquirem espaço no processo escolar, colaboram junto com a razão crítica como alternativas viáveis ao processo educacional. A educação na prática da escola, a partir do modelo pós-moderno, engendra procedimentos que correspondem à realidade. Como na visão de Freire, a educação é diálogo, na medida em que os sujeitos buscam a significação para a sua realidade. A ela não pode ser dada de forma autoritária, mas tem que abarcar um sentido para a realidade do aluno, é na composição dialógica que os indivíduos se tornam atores do universo escolar.
\end{abstract}

Dessa forma, é importante retomar autores que discutem sobre a formação temática e a didática, bem como outros pontos do universo da inclusão escolar. Visto que a percepção dos debates e compartilhamentos de ideias e teorias ainda não é a mesma da observação direta e atuação prática na escola convencional. Além disso, é fundamental pensar na formação em Empreendedorismo, Inclusão, Interdisciplinaridade e Sustentabilidade, elos da Educação póscontemporânea nos cursos de Licenciatura, que apresentem mecanismos práticos para auxiliar nas eventuais dificuldades do futuro mestre.

É a Educação Empreendedora, Inclusiva, Interdisciplinar e Sustentável que se consolida. Se existem espaços relevantes de discussão, a coletividade brasileira caminha na construção de participação efetiva do educando em todos os espaços sociais que lhe conferem as prerrogativas legais vigentes (BRASIL, 1988). Assim desconstruindo históricos estereótipos preteritamente vinculados à Educação pós-contemporânea insere-se a carga horária de estágios, que legalmente contempla uma carga horária de teoria e prática a partir da observação in loco. Apesar da consolidação do estágio, enquanto elemento de formação docente, as temáticas do Empreendedorismo, da Interdisciplinaridade e da Sustentabilidade ainda se encontram em ritmo lento, ao contrário da Inclusão, cuja emergência e legalidade eclodiu veementemente nas duas últimas décadas, sendo uma das principais premissas do Século XII. Uma análise teórica associada à atuação prática em todos os espaços pedagógicos, da escola e da sociedade possibilitam ao docente, a reflexão sobre seu posterior trabalho de transformação da realidade de limitação, ao qual espaços educacionais ainda consolidam, 
O cenário da pós-modernidade, marcado pela problemática filosófica do século XX, ocupa no pensamento contemporâneo discussões polêmicas acerca do conhecimento no âmbito da educação. A relação entre pós-modernidade e educação tem sido objeto de polêmicas, desde o começo a ideia de pós-modernidade trouxe implicações para a produção de conhecimento no campo da filosofia e da ciência. Com a crise da modernidade e suas teorias metafísicas, as teorias pedagógicas também tiveram seus fundamentos reduzidos à condição de incredulidade. É no momento do contemporâneo que a ideia de pós-modernidade introduz a mudança de modelo em todos os campos do conhecimento humano determinando a condição pós-moderna como base de questionamentos e indeterminações.

Os Cursos de Licenciatura oferecidos em todas as instituições públicas ou privadas do Brasil, seja no ensino presencial ou à distância, oferecem legalmente ao futuro licenciado, as disciplinas de estágios curriculares obrigatórios supervisionados, cujo objetivo é proporcionar o aprendizado de competências próprias da atividade profissional e a contextualização curricular com o desenvolvimento do educando para a vida cidadã e para o trabalho. O estágio curricular obrigatório supervisionado, seguindo recomendação da Comissão Nacional de Reformulação dos Cursos de Formação de Educadores, aponta para a integração teoria-prática do fazer/pensar pedagógico como um dos eixos de formação dos profissionais da educação pós-contemporânea, realizando-se em situações reais, isto é, em unidades escolares dos sistemas de ensino da educação básica brasileira: educação infantil e educação básica (anos iniciais e finais do Ensino Fundamental e Ensino Médio). Neste contexto, além das já observações, intervenções e regências previstas nos estágios, é indispensável a percepção de lacunas e avanços na construção de uma Escola Empreendedora, Inclusiva, Interdisciplinar e Sustentável, conforme detalhamentos temáticos no dicionário do Quadro I.

Quadro I - Escola Empreendedora, Inclusiva, Interdisciplinar e Sustentável: significados

\begin{tabular}{|c|c|}
\hline Palavra & Significado \\
\hline $\begin{array}{l}\text { Aluno empreendedor } \\
\text { (Princípio do } \\
\text { Empreendedorismo) }\end{array}$ & $\begin{array}{l}\text { (Substantivo masculino) Capacidade de projetar novos negócios ou de idealizar } \\
\text { transformações inovadoras ou arriscadas em companhias ou empresas. Vocação, } \\
\text { aptidão ou habilidade de desconstruir, de gerenciar e de desenvolver projetos, } \\
\text { atividades ou negócios. Reunião dos conhecimentos e das aptidões relacionadas } \\
\text { com essa capacidade. Etimologia (origem da palavra empreendedorismo). } \\
\text { Empreendedor + ismo }\end{array}$ \\
\hline $\begin{array}{c}\text { Aluno Inclusivo } \\
\text { (Princípio do Inclusão }\end{array}$ & $\begin{array}{l}\text { (Substantivo feminino) Integração absoluta de pessoas que possuem necessidades } \\
\text { especiais ou específicas numa sociedade: políticas de inclusão. }\end{array}$ \\
\hline $\begin{array}{l}\text { Aluno Interdisciplinar } \\
\text { (Princípio do } \\
\text { Interdisciplinaridade }\end{array}$ & $\begin{array}{l}\text { (Substantivo feminino) Qualidade do que é interdisciplinar, comum a duas ou } \\
\text { várias disciplinas: há interdisciplinaridade quando o professor de biologia trabalha } \\
\text { juntamente com o de química. Capaz de estabelecer relações entre duas ou mais } \\
\text { disciplinas, ou áreas do conhecimento, com o intuito de melhorar o processo de } \\
\text { aprendizagem, estreitando a relação entre professor e aluno. Etimologia (origem da } \\
\text { palavra interdisciplinaridade). Inter + disciplina + idade. }\end{array}$ \\
\hline $\begin{array}{l}\text { Aluno Sustentável } \\
\text { (Princípio do } \\
\text { Sustentabilidade }\end{array}$ & $\begin{array}{l}\text { (Substantivo feminino) Conceito que, relacionando aspectos econômicos, sociais, } \\
\text { culturais e ambientais, busca suprir as necessidades do presente sem afetar as } \\
\text { gerações futuras. Qualidade ou propriedade do que é sustentável, do que é } \\
\text { necessário à conservação da vida. Etimologia (origem da palavra sustentabilidade). } \\
\text { Sustentável - vel + bil(i) + dade. }\end{array}$ \\
\hline
\end{tabular}

Fonte: https://www.dicio.com.br/ 
Dentre as etapas para o desenvolvimento do Estágio Supervisionado, a primeira é o conhecimento da escola, espaço na qual se inicia o trabalho de observação que se dará semanalmente ou diariamente ou quinzenalmente ou mensalmente de acordo com prerrogativas de cada colegiado e coordenação de curso. Todo trabalho resultará em um projeto de estágio curricular obrigatório que atenderá a proposta na lei $\mathrm{n}^{\circ} 11.788 / 2008$, que em artigo $1^{\circ}$ delibera sobre "à preparação de trabalho produtivo do educando".

\section{LEI No 11.788 , DE 25 DE SETEMBRO DE 2008}

Dispõe sobre o estágio de estudantes; altera a redação do art. 428 da Consolidação das Leis do Trabalho - CLT, aprovada pelo Decreto-Lei $\mathrm{n}^{\circ} 5.452$, de $1^{\circ}$ de maio de $1943^{4}$, e a Lei n ${ }^{\circ} 9.394$, de 20 de dezembro de $1996^{5}$; revoga as Leis n ${ }^{\circ}$ s 6.494 , de 7 de dezembro de $1977^{6}$, e 8.859 , de 23 de março de $1994^{7}$, o parágrafo único do art. 82 da Lei $n^{\circ} 9.394$, de 20 de dezembro de 1996, e o art. $6^{\circ}$ da Medida Provisória ${ }^{\circ}$ 2.164-41, de 24 de agosto de $2001^{8}$; e dá outras providências.

O PRESIDENTE DA REPÚBLICA Faço saber que o Congresso Nacional decreta e eu sanciono a seguinte Lei:

CAPÍTULO I DA DEFINIÇÃO, CLASSIFICAÇÃO E RELAÇÕES DE ESTÁGIO

Art. $1^{\circ}$ Estágio é ato educativo escolar supervisionado, desenvolvido no ambiente de trabalho, que visa à preparação para o trabalho produtivo de educandos que estejam freqüentando o ensino regular em instituições de educação superior, de educação profissional, de ensino médio, da educação especial e dos anos finais do ensino fundamental, na modalidade profissional da educação de jovens e adultos.

$\S 1^{\circ} \mathrm{O}$ estágio faz parte do projeto pedagógico do curso, além de integrar o itinerário formativo do educando.

$\S 2^{\circ} \mathrm{O}$ estágio visa ao aprendizado de competências próprias da atividade profissional e à contextualização curricular, objetivando o desenvolvimento do educando para a vida cidadã e para o trabalho.

O estágio curricular obrigatório supervisionado caracteriza-se como o exercício da experiência prática, teórica profissional, por meio de uma vivência em ambientes escolares e não escolares, levando o aluno da licenciatura à interpretação da realidade educacional nas instituições de ensino. Três objetivos principais fundamentam e legitimam a importância do estágio, curricular obrigatório destacados por Viegas (2018, p. 08):

5 LEI N ${ }^{\circ}$ 9.394, DE 20 DE DEZEMBRO DE 1996 - Estabelece as diretrizes e bases da educação nacional (Vide Decreto $n^{\circ} 3.860$, de 2001), (Vide Lei no 10.870, de 2004), (Vide Adin 3324-7, de 2005), (Vide Lei $n^{\circ} 12.061$, de 2009).

6 LEI No 6.494, DE 7 DE DEZEMBRO DE 1977. Revogada pela Lei $\mathrm{n}^{\circ}$ 11.788, de 2008, dispõe sobre os estágios de estudantes de estabelecimento de ensino superior e ensino profissionalizante do $2^{\circ}$ Grau e Supletivo e dá outras providências.

7 LEI No 8.859, DE 23 DE MARÇO DE 1994. Revogada pela Lei n $^{0} 11.788$, de 2008, modifica dispositivos da Lei $\mathrm{n}^{\circ}$ 6.494, de 7 de dezembro de 1977, estendendo aos alunos de ensino especial o direito à participação em atividades de estágio.

8 Art. 82. Os sistemas de ensino estabelecerão as normas para realização dos estágios dos alunos regularmente matriculados no ensino médio ou superior em sua jurisdição.

Parágrafo único. O estágio realizado nas condições deste artigo não estabelecem vínculo empregatício, podendo o estagiário receber bolsa de estágio, estar segurado contra acidentes e ter a cobertura previdenciária prevista na legislação específica. Parágrafo único. (Revogado). (Redação dada pela Lei nº 11.788, de 2008).

Art. 82. Os sistemas de ensino estabelecerão as normas de realização de estágio em sua jurisdição, observada a lei federal sobre a matéria. (Redação dada pela Lei nº 11.788, de 2008). 
1. Possibilitar ao futuro docente a reflexão, seleção e priorização de situaçõesproblema reais, sob a orientação segura e cuidadosa para aprofundamento teórico da prática educativa, numa tentativa de melhoria qualificativa dessa prática;

2. Possibilitar a vivência real e objetiva da futura profissão junto às instituições de Ensino em diversos contextos e situações: públicas, privadas, de centro e de periferias;

3. Fornecer sólida fundamentação teórica que possibilite ao acadêmico analisar criticamente a prática pedagógica das Instituições Escolares e, posteriormente, ter elementos teórico/práticos para analisar a sua própria prática pedagógica;

Por meio dos estágios curriculares obrigatórios supervisionados legalmente é possível consolidar os conhecimentos adquiridos no decorrer do curso e estabelecer relação entre teoria e prática. Sendo assim, o estágio curricular supervisionado se torna um componente curricular obrigatório que proporciona ao estudante de licenciatura, a reflexão contextualizada, dando condições para que se torne autor de sua própria prática.

\section{O ESTÁGIO SUPERVISIONADO ENQUANTO IDENTIDADE PROFISSIONAL DO PRECEPTOR}

Ao discorrer sobre o estágio curricular obrigatório supervisionado é fundamental pensar em alguns pontos como a didática, a formação prática nos diferentes cursos de licenciatura (Quadro II) e a reflexão da atuação técnica em articulação à teoria. Assim, a didática relaciona-se diretamente ao contexto sociocultural, reforçando que as aulas serão planejadas de acordo com necessidade da escola e de sua comunidade adjacente. Então, a didática escolar parte da realidade escolar na qual à diversidade sociocultural, às diferenças e divergências precisam ser equacionadas na construção dos atores socioculturais, enquanto cidadãos do futuro. Além disso, não se abandona a pesquisa, pois "não há ensino sem pesquisa e pesquisa sem ensino" (FREIRE, 1996, p. 29), sendo primordial e efetivamente inegável e irrevogável a experiência na escola, pois não se forma profissional sem o contato direto com sua futura área de atuação. Complementando isso, Freire (1996, p. 23) afirma que "não há docência sem discência". Logo, o professor é percebido como educando, visto que aprende ao ensinar e ensina ao aprender, uma dualidade constante em seu trabalho. Para Scalabrin e Molirani (2013, p. 01-02):

O Estágio Curricular Supervisionado, indispensável na formação de docentes nos cursos de licenciatura é um processo de aprendizagem necessário a um profissional que deseja realmente estar preparado para enfrentar os desafios de uma carreira e deve acontecer durante todo o curso de formação acadêmica, no qual os estudantes são incentivados a conhecerem espaços educativos entrando em contato com a realidade sociocultural da população e da instituição. Como preparação à realização da prática em sala de aula, o tradicional estágio se configura como uma possibilidade de fazer uma relação entre teoria e prática, conhecer a realidade da profissão que optou para desempenhar, pois, quando o acadêmico tem contato com as atividades que o estágio lhe oportuniza, inicia a compreensão aquilo que tem 
VIEGAS, G. G. Z; COSTA, L; ANDRADE, G. L.

Prática no Estágios Supervisionado para Educação Pós-Contemporânea: A Contribuição Teórica do Empreendedorismo, Inclusão, Interdisciplinaridade e Sustentabilidade na Formação do Professor estudado e começa a fazer a relação com o cotidiano do seu trabalho. Além disso, o aprendizado é muito mais eficiente quando é obtido através da experiência; na prática o conhecimento é assimilado com muito mais eficácia, tanto é que se torna muito mais comum ao estagiário lembrar-se de atividades durante o percurso do seu estágio do que das atividades que realizou em sala de aula enquanto aluno. $\mathrm{Na}$ efetiva prática de sala de aula o estagiário tem a possibilidade de entender vários conceitos que lhe foram ensinados apenas na teoria. Por isso, o estudante deve perceber no estágio uma oportunidade única e realizá-lo com determinação, comprometimento e responsabilidade. Seria apenas um desgaste caso não houvesse interesse em aprender e preparar-se para a

Quadro II - Relação de Estágios em diferentes licenciaturas, na modalidade à distância, numa IES privada

\begin{tabular}{|l|c|c|c|}
\hline \multicolumn{1}{|c|}{ Etapa do Curso } & FP & LP & SL \\
\hline \multicolumn{1}{|c|}{ Estágio Curricular Obrigatório Supervisionado } & 01 & 03 & 01 \\
\hline Artes Visuais & 01 & 03 & 01 \\
\hline Ciências Biológicas & 01 & 03 & 01 \\
\hline Educação Especial & 01 & 03 & 01 \\
\hline Educação Física & 01 & 03 & 01 \\
\hline Educação Religiosa & \multicolumn{2}{|c|}{ Curso Inexistente } \\
\hline Filosofia & 01 & 03 & 01 \\
\hline Física & 01 & 03 & 01 \\
\hline Geografia & 01 & 03 & 01 \\
\hline História & 01 & 03 & 01 \\
\hline Informática & 01 & 03 & 01 \\
\hline Letras - Espanhol & 01 & 03 & 01 \\
\hline Letras - Inglês & 01 & 03 & 01 \\
\hline Letras - LIBRAS & 01 & 03 & 01 \\
\hline Letras - Português & 01 & 03 & 01 \\
\hline Matemática & 01 & 03 & 01 \\
\hline Pedagogia & 01 & 03 & 01 \\
\hline Química & 01 & 03 & 01 \\
\hline Sociologia & 01 & 03 & 01 \\
\hline
\end{tabular}

FP - Formação Pedagógica; LP - Licenciatura Plena; SL -- Segunda Licenciatura Fonte: https://portal.uniasselvi.com.br/graduacao

A formação do licenciado engloba um aprendizado contínuo envolvendo a relação educador/aluno, bem como a percepção de como se consolida o trabalho pedagógico. A partir de observações e sondagens dentro da escola, traça-se um perfil do profissional que está atuando naquele ambiente, além da articulação sobre o que foi discutido teoricamente no curso de graduação. Neste sentido, retoma-se a ideia de Dayrell (1996), que a escola é um espaço sociocultural, ambiente de ações analisadas de acordo com um determinado contexto social e cultural, produzido historicamente. Entendem-se, a partir da observação prática, as necessidades e demandas educacionais associando experiências, teorias e discussão, validando-as. Por isso, o mestre terá uma formação que contemple essa visão, para o exercício futuro de lidar nas diferentes situações e desafios educativos com autonomia, ética e profissionalismo buscando ajuda quando necessário. A pedagogia da autonomia centra-se em experiências respeitosas e estimuladoras da decisão, da liberdade e da responsabilidade (FREIRE, 1996, p. 121). Corte e Lemke (2015, p. 009-010) defendem que: 
A docência comporta vários saberes: conhecimento, compreensão, motivação, empatia, competência, paciência, didática, criatividade etc. Portanto, o conhecimento, por si só, não é suficiente na prática docente. O professor deve saber ensinar, ou seja, saber sobre educação, pedagogia e didática de sua matéria para que consiga imprimir ao seu conteúdo um caráter de conhecimento e não apenas de informação. O ensino, portanto, deve ser inovador e não mantenedor. Frente a isso, percebe-se que é preciso usar novos mapas para velhas rotas, fazer com que os alunos construam um sentido significativo para o que aprendem, para suas vidas, o que corresponde a ouvir, refletir, analisar, compreender o que dizem e fazem; corresponde a captar a problemática econômica, social e política dos que estão inseridos nessa realidade e a bagagem de conhecimentos trazidas por eles. É importante salientar que o processo de formação é apenas iniciado durante a graduação, sendo indispensável a formação continuada e atualização constante desse profissional. Além disso, outro aspecto importante da formação docente é o de que não é apenas a disciplina de estágio supervisionado a responsável por essa formação, pois cabe, também, às outras disciplinas, o papel de formadoras. Sendo assim, percebe-se que a formação docente perpassa as instâncias do conhecimento científico e metodológico. Frente aos novos desafios é preciso formar e formar-se enquanto profissional reflexivo, autônomo, capaz de compreender a realidade em que atua e seu papel nesta realidade. Além disso, este novo profissional, formado em um e para um contexto de mudança precisa colocar-se na condição de agente transformador da realidade na qual atua.

Para ensinar é importante conhecer a contemporaneidade das questões pedagógicas e didáticas, além do domínio da prática e da teoria. É interessante retomar o pensamento de Pimenta (1997) quando ele discute sobre a constante atualização da Ciência Didática, após o movimento de sua negação e sua crítica, na década de 1950, contextualizando permanências e rupturas. Entende-se que a atuação prática do futuro docente é essência para construção de novos conhecimentos da contemporaneidade, em especial, uma Didática Empreendedora, Inclusiva, Interdisciplinar e Sustentável. Neste sentido, na docência, é necessária a reflexão teórica consolidada após a observação prática articuladora da realidade e das necessidades didáticas do aluno. Logo, é fundamental pensar uma nova identidade para a Ciência Didática e, portanto, para o licenciado, profissional da educação pós-contemporânea. Essa identidade é teoricamente constituída a partir do significado prático da profissão numa sociedade em constantes reformulações. Educar em tempos recentes é ir além dos conhecimentos e da experiência docente, protagonizando processos de transformação da realidade sociocultural enfatizando elementos empreendedores, inclusivos, interdisciplinares e sustentáveis. É fundamental para os futuros preceptores, que a partir do estágio curricular obrigatório supervisionado, percebam o perfil de profissional atuante na escola configurado de acordo com sua formação e seu espaço de trabalho. Nesse processo, o educador e a escola articuladamente contribuem para o desenvolvimento cultural, intelectual e social dos estudantes, pois de acordo com Pimenta (1997, p. 57):

A partir de então é possível problematizar o que entendemos ser, hoje, a finalidade da Didática: estudar o fenômeno ensino como prática social. Isto é, admitindo suas múltiplas determinações - subjetivas, familiares, de grupos sociais, escolares, 

sociais -, compreender as gêneses de seus resultados, ou seja, como se processam os fracassos e os sucessos escolares. Compreender para criar melhores formas e processos de viabilizar uma educação escolar emancipatória das crianças e dos jovens (PIMENTA, 1997, p. 57).

Desse modo, vê-se que o docente busca continuamente uma formação empreendedora, inclusiva, interdisciplinar e sustentável constante, entendendo a relevância dos contextos sociais e históricos da atualidade, bem como os elementos pessoais e culturais que estão envolvidos no processo de ensino/aprendizagem. Assim, Piconez (2010) ressalta que o estágio curricular obrigatório supervisionado é um componente teórico-prático que apresenta uma caracterização ideal, subjetiva e teórica relacionadas às questões sociais, reais e da prática pedagógica considerando todo o contexto escolar, sua amplitude e correlações. Já que a educação pós-contemporânea passa efetivamente por transformações constantes e se atenta aos desafios surgidos, sendo impreterivelmente necessário que a formação se articule com essas demandas empreendedoras, inclusivas, interdisciplinares e sustentáveis.

\section{EMPREENDEDORISMO, INCLUSÃO, INTERDISCIPLINARIDADE E SUSTENTABILIDADE ENQUANTO ELOS DE OBSERVAÇÃO E VIVÊNCIA NO ESTÁGIO: A ARTICULAÇÃ̃ ENTRE TEORIA E PRÁTICA}

Imagine uma nova ordem social verdadeiramente empreendedora, inclusiva, interdisciplinar e sustentável? Pois é, os diversos desafios impostos pela póscontemporaneidade exigem cada vez mais do/a homem/mulher uma formação plena, integradora e sistêmica que contemple não somente os aspectos educacional e profissional, mas, sobretudo, elementos primordiais no que se refere à essência humana. Neste sentido, uma formação educacional plena dos novos docentes, perpassa por uma integração sistemática, entre os aspectos ambiental, cultural e social que por sua vez caracterizam a realidade vivenciada, independente de idade, credo, raça, condição física e/ou status socioeconômico, contribuindo assim efetivamente para a qualidade de vida e exercício da cidadania. Pensando nesta nova perspectiva surge a construção de propostas atreladas a uma nova concepção de mundo pautada em quatro pilares contemporâneos básicos: Empreendedorismo, Inclusão, Interdisciplinaridade e Sustentabilidade, numa perspectiva filosófica, pedagógica e sociológica, objetivando contribuir para se repensar e reformular a relação entre homem, cultura, sociedade e natureza. Desenvolver a atuação no estágio, e posteriormente na docência de uma nova prática educativa, que promova a integração interdisciplinar, multidisciplinar e transdisciplinar entre Ética, Educação e Mobilização contribuindo efetivamente com a formação plena do ser humano. Oliveira, Abreu e Oliveira (2013, p. 185) discorrem que: 
A perspectiva da educação pós-moderna, em oposição à teoria tradicional em educação, afirma a necessidade de atitudes críticas e transformadoras no universo escolar (PAGNI, 2006 ${ }^{9}$ ). É uma tentativa de superar as desigualdades criadas pelo modelo moderno de educação, proporcionando ao aluno e ao professor abertura para o diálogo e o consenso entre educação e realidade. As considerações acerca dos conflitos educacionais no mundo contemporâneo levam-nos à tomada de decisões enquanto educadores, no sentido em que direcionamos metas de superação da crise na educação e criamos fundamentos para uma educação pós-moderna, na medida em que haja comprometimento de considerações necessárias para o conhecimento na produção de educação. A visão da pós-modernidade em educação é entendida pela multiplicidade de ideias em oposição à razão universalista. A educação pós-moderna oferece referenciais importantes para educadores e educandos, pois se propõe a vivenciar o mundo pluralista12 e mutável, na medida em que aprimora e supera os conceitos da tradição moderna, permitindo conexões com a realidade sócioeducacional de cada indivíduo, com objetivo de construir educação criativa (PAGNI, 2006). Partilhar as ideias pluralistas na educação é possibilitar que o aluno emita opiniões, é gerar discussões de interação que possibilitem a formação de cidadãos capazes de pensar e planejar processos de transformações sociais e, principalmente, educacionais. Tendo em vista esses pressupostos da educação pós-moderna, consideramos que essas atitudes são importantes para o incentivo das ações pedagógicas, bem como também, são adequadas para a formação do ser humano.

No estágio curricular obrigatório supervisionado, percebe-se, além das questões referentes à construção de uma identidade do professor em posicionamento aos desafios póscontemporâneos vivenciados na educação empreendedora, inclusiva, interdisciplinar e sustentável, verifica-se, em alguns casos, a total desarticulação entre teoria e prática, elementos indissociáveis. Parte-se do princípio de que ambos são fundamentais à construção as premissas educativas e estão interligados. É fundamental que o educador perceba que a ação docente na escola é estudada em meios acadêmicos para ajudar na superação de problemas pretéritos e atuais, bem como é uma forma de buscar novos modos de reflexão sobre as demandas atuais da educação pós-contemporânea no âmbito do projeto de sociedade. Gómez (1997, p.103) acredita que é importante refletir a prática, pois a.

Imersão consciente do homem no mundo da sua experiência, um mundo carregado de conotações, valores, intercâmbios simbólicos, correspondências afetivas, interesses sociais e cenários políticos. O conhecimento acadêmico, teórico, científico ou técnico, só pode ser considerado instrumento dos processos de reflexão se for integrado significativamente, [...] em esquemas de pensamento mais genérico ativados pelo indivíduo quando interpreta a realidade concreta em que vive e quando organiza a sua própria experiência.

Neste sentido, é necessário que os cursos de formação do profissional da educação pós-contemporânea estejam atentos às angústias da prática docente, relacionando e conectando ininterruptamente, teoria e prática, permitindo a promoção do conhecimento pedagógico e científico. Por ser uma parceria efetiva entre escola e universidade, aproximamse, de antes de tudo, os pensamentos teóricos da atuação pedagógica, contemplando reflexões 
dentro do curso de licenciatura por meio de discussões sobre os anseios do futuro mestre. "É preciso que os professores orientadores de estágios curriculares obrigatórios procedam no coletivo, junto a seus pares e alunos, a essa apropriação da realidade, para analisá-la e questioná-la criticamente, à luz de teorias" (PIMENTA; LIMA, 2004, p. 45). Buscando, assim, uma forma de integração contínua na busca por reafirmações, construções, reconstruções e desconstruções do tempo presente e de suas urgências empreendedoras, inclusivas, interdisciplinares e sustentáveis. Segundo Oliveira, Abreu e Oliveira (2013, p. 183)

\begin{abstract}
Parece provável que o modelo de educação privilegia o método instrumental, voltado para conteúdos estritamente técnicos que descartam a possibilidade de indivíduos reflexivos e críticos. Decorrente da necessidade atual da ideia pósmoderna de educação, tende a inserir novas formas de ensino que estimulam os diferentes indivíduos ao desenvolvimento do pensamento reflexivo, visando a atender dessa forma a condição da educação no âmbito da pós-modernidade. A compreensão do homem moderno é questionada pela nova postura de pensamento, que constitui não apenas como crítica de uma racionalidade cultural moderna, mas tem como principal desafio os limites do próprio conhecimento, pois conhecimento e cultura estão intrinsecamente relacionados à educação. A perspectiva do pensamento pós-moderno em educação é a tentativa de superação da pedagogia modernista de fundamentação em verdades universais que produzem discursos teleológicos. Assim, com base na reação e redefinição da cultura, a pós-modernidade se propõe, no momento de crise da modernidade no campo da educação, a mudanças cada vez mais rápidas.
\end{abstract}

A escola tem avançado na pauta inclusiva, sendo necessário trazer outras pautas pósmodernas. Isso se consolidou, em parte, a Lei de Diretrizes e Bases da Educação Nacional LDBEN, definida em 20 de dezembro de 1996, através da Lei federal nº 9.394 (Brasil, 1996), mais precisamente, no Capítulo III, art. $4^{\circ}$, inciso III, diz que é dever do Estado garantir o "atendimento educacional especializado gratuito aos educandos com necessidades especiais, preferencialmente na rede regular de ensino". Inclusive, o capítulo 5 da respectiva LDBEN trata somente de aspectos referentes à Educação Especial. Entre os pontos especificados, o art. 58. $\S 1^{\circ}$ profere que, sempre que necessário, haverá serviços de apoio especializado para atender às necessidades peculiares de cada aluno portador de necessidades especiais. Daí a importância do futuro mestre, no âmbito dos estágios curriculares obrigatórios supervisionados, de reconhecer currículos diferenciados e iniciar com um olhar crítico e sensível às práticas pedagógicas de inclusão. $\mathrm{O}$ avanço nesta temática tem enunciados a necessidade de mais avanços para se consolidar uma escolar empreendedora, interdisciplinar e sustentável. Silva e Gaspar (2018, p 207) verificam que:

A Lei $\mathrm{n}^{\circ}$ 11.788, de 25 de setembro de 2008 (Brasil, 2008), estabelece a normatização do estágio dos estudantes, discorrendo sobre o obrigatório e o não obrigatório (Art. $2^{\circ}$ ). De acordo com a lei, o estágio é um "ato educativo escolar supervisionado, desenvolvido no ambiente de trabalho, que visa à preparação para o trabalho produtivo do estudante". No que diz respeito aos envolvidos nesse 
processo, a lei evidencia a articulação entre ensino e campo de trabalho para a realização do estágio, ressaltando a participação das instituições concedentes (campo do estágio), visto que este é um "compromisso formalizado entre o estagiário, a instituição de ensino e a empresa com base em um plano de atividade que materializa a extensão ao ambiente de trabalho do projeto pedagógico desenvolvido nas disciplinas do currículo escolar". É importante salientar que essa lei traz, nos Arts. $2^{\circ}$ e 16 , o termo de compromisso entre a instituição de formação profissional e a instituição concedente do estágio, garantindo, assim, a realização deste, pois estabelece as atividades a serem desenvolvidas pelo aluno estagiário.

Complementando esse pensamento, Freire (1996) entende que para superar a questão dicotômica entre teoria e prática, é necessário um desenvolvimento crítico, tendo uma aceitação ao novo e rejeitando quaisquer meios de discriminação e indiferença. Logo, os cursos de Licenciaturas em ofertas por todo país, se atualizarão e criarão uma parceira com as escolas de forma que ambos contribuam para uma formação curricular ampla que atenda as demandas educacionais, bem como ajudam os novos profissionais da educação póscontemporânea em suas adaptações e necessidades pedagógicas.

\section{CONSIDERAÇÕES FINAIS}

O estágio curricular obrigatório supervisionado é um momento relevante e único de construção de conhecimento teórico-prático, bem como de compartilhamento de ideias e indagações, propiciando o contato direto, crítico e analítico com a didática e a dinâmica escolar. Discorrer mais sobre o valor destes eixos na formação docente e discente em tempos atuais, se faz urgente. A partir da percepção das múltiplas possibilidades de atuação pedagógica, percebe-se que é necessária uma imediata articulação entre teoria e prática, visto que a busca por conhecimento deva ser constante no exercício da docência. Neste sentido, os cursos de formação em educação pós-contemporânea, em especial, a licenciatura, através da oferta regular de estágios curriculares obrigatórios supervisionados ajuda os futuros professores na reflexão crítica sobre a prática escolar, seus dilemas e desafios.

Além disso, o estágio curricular obrigatório, além de componente obrigatório para a integralização curricular e consecutiva colação de grau contribui efetivamente para a percepção da ciência didática como um importante meio para à consolidação da experiência docente. Mas, além disso, é uma forma significativa de entendimento teórico-prático sobre as demandas educacionais da contemporaneidade: empreendedora, inclusiva, interdisciplinar e sustentável. Sabe-se que a teoria ajuda as ações docentes por meio de reflexões, discussões e reformulações sobre a prática e o fazer pedagógico para a transformação sociocultural. $\mathrm{O}$ mestre busca sucessivamente uma formação contínua, considerando o contexto social e cultural dos alunos, numa totalidade de adversidades, diversidades e riquezas.

É no chão da escola que as vivências pedagógicas surgem, se fazem e se refazem 
proporcionando ao estudante e futuro docente à luz crítica e criativa do conhecimento pedagógico, reafirmando-o e legitimando-o. As teorias pedagógicas caminham lado a lado com as práticas educativas, nos quais as questões empreendedoras, inclusivas, interdisciplinares e sustentáveis estarão presentes. Logo, o estágio curricular obrigatório é um elemento fundamental na formação do licenciado, possibilitando uma visão ampla e crítica da situação escolar e do contexto educacional vigente, efetivando um espaço para reflexão teórico-prática, permitindo uma formação que visa a construção do conhecimento e sua efetiva inserção, enquanto elo de uma nova ordem social, no qual se emancipe e protagonizem novos modelos societários. Alunos empreendedores, inclusivos, interdisciplinares e sustentáveis requerem uma formação mais qualificada por parte dos licenciados, sendo importante caminhar para além da vivência do estágio vinculados à essas temáticas contemporâneas. Sobretudo, Empreendedorismo, Inclusão, Interdisciplinaridade e Sustentabilidade devem ser disciplinas obrigatórias na formação dos futuros professores.

\section{REFERÊNCIAS}

BRASIL, República Federativa do. Comissão Nacional de Reformulação dos Cursos de Formação de $\quad$ Educadores. $\quad$ Disponível em http://www.lite.fe.unicamp.br/grupos/formac/comiss\%E3o_nacional_de_reformula\%E7\%E3. htm Acesso em 05. Jan. 2021

BRASIL, República Federativa do. Conselho Nacional de Educação (CNE). Resolução $\mathrm{CNE} / \mathrm{CP} \mathbf{n}^{\circ}$ 1, de 18 de fevereiro de 2002. Institui Diretrizes Curriculares Nacionais para a Formação de professores da Educação Básica, em nível superior. Brasília: Diário Oficial da União, 4 mar. 2002a. Seção 1, p. 8.

BRASIL, República Federativa do. Conselho Nacional de Educação (CNE). Resolução $\mathrm{CNE} / \mathrm{CP} \mathbf{n}^{\circ}$ 2, de 19 de fevereiro de 2002. Duração e carga horária dos cursos de licenciatura, de graduação plena, de formação de professores para Educação Básica, em nível superior. Diário Oficial da União, Brasília, 4 mar. 2002-b. Seção 1, p. 9.

BRASIL, República Federativa do. Lei Federal no 9.394 de 20/12/1996 Estabelece a Lei de Diretrizes e Bases da Educação Nacional (LDB). Disponível em http://www2.camara.leg.br/legin/fed/lei/1996/lei-9394-20-dezembro-1996-362578publicacaooriginal-1-pl.html Acesso em 05. Jan. 2021

BRASIL, República Federativa do. Lei $\mathbf{n}^{\mathbf{0}}$ 11.788, de 25 de setembro de 2008. Dispõe sobre o estágio de estudantes. Diário Oficial da União, Brasília, 26 set. 2008. Seção 1, p. 3.

\section{BRASIL, República Federativa do. Política Nacional de Educação Especial na perspectiva} da educação $\quad$ Inclusiva. $2008 . \quad$ Disponível http://portal.mec.gov.br/index.php?option=com_docman\&view=download\&alias=16690politica-nacional-de-educacao-especial-na-perspectiva-da-educacao-inclusiva05122014\&Itemid=30192. Acesso em 05. Jan. 2021 
BRASIL. Constituição $\quad$ Federal Disponível em http://www.planalto.gov.br/ccivil_03/Constituicao/Constituicao.htm. Acesso em 05. Jan. 2021

CORTE, Anelise C. Dalla. Lemke, Cibele K. O ESTÁGIO SUPERVISIONADO E SUA IMPORTÂNCIA PARA A FORMAÇÃO DOCENTE FRENTE AOS NOVOS DESAFIOS DE ENSINAR. $\quad$ Disponível em http://educere.bruc.com.br/arquivo/pdf2015/22340_11115.pdf. Acesso em 05. Jan. 2021

DAYRELL, Juarez. A escola como espaço sociocultural. In: DAYRELL, Juarez. Múltiplos olhares sobre educação e cultura. Belo Horizonte: UFMG, 1996.

FREIRE, Paulo. Pedagogia da Autonomia: saberes necessários à prática educativa. São Paulo: Paz e Terra, 1996.

GOMÉZ, A. O pensamento prático do professor: a formação do professor como profissional reflexivo. In: NOVA, A (Coord.). Os professores e sua formação. Lisboa: Dom Quixote, 1995. p. 93-114.

OLIVEIRA, Cássia Araújo de, ABREU, Waldir Ferreira de, OLIVEIRA, Damião Bezerra. Conhecimento e educação na pós-modernidade. Revista Margens Interdisciplinar. v. 7, n. 8, p. 175-188, 2013.

PICONEZ, Stela C. Bertholo. A prática de ensino e o estágio supervisionado: a aproximação da realidade escolar e a prática da reflexão. 23. ed. Campinas, SP: Papirus, 2010.

PIMENTA, S. G. A didática como mediação na construção de identidade do professor - uma experiência de ensino na licenciatura. In: OLIVEIRA, M. R. N. S.; ANDRÉ, M. E. D. A. de. (org.). Alternativas no ensino de didática. Campinas, SP: Papirus, 1997.p.37-70

PIMENTA, Selma Garrido. Estágio na formação de professores: unidade, teoria e prática? São Paulo: Cortez, 2011.

PIMENTA, Selma Garrido; LIMA, Maria Socorro Lucena. Estágio e Docência. São Paulo: Cortez, 2004.

SCALABRIN, Izabel Cristina. MOLINARI, Adriana Maria Corder. A IMPORTÂNCIA DA PRÁTICA DO ESTÁGIO SUPERVISIONADO NAS LICENCIATURAS. Disponível em http://revistaunar.com.br/cientifica/documentos/vol7_n1_2013/3_a_importancia_da_pratica_e stagio.pdf. Acesso em 05. Jan. 2021

SILVA, Haíla Ivanilda. GASPAR, Mônica. Estágio supervisionado: a relação teoria e prática reflexiva na formação de professores do curso de Licenciatura em Pedagogia. Disponível em http://www.scielo.br/pdf/rbeped/v99n251/2176-6681-rbeped-99-251-205.pdf. Acesso em 05. Jan. 2021

SILVA, Mônica Caetano Vieira da; URBANETZ, Sandra Terezinha (Orgs.). O Estágio no curso de pedagogia. Curitiba: Ibpex, 2009. (Série TCC e Estágio em Pedagogia). v. 1.

SOUZA, Elizeu Clementino de. O conhecimento de si: estágio e narrativas de formação de professores. Rio de Janeiro: DP\&A, 2006.

VIEGAS, Geiza Gláucia Zeferino. A contribuição do estágio supervisionado: a teoria e a 
Artigo Recebido: 29 de março de 2021.

Artigo Aceito: 30 de abril de 2021. 